\title{
Reduction of Iron Ores in the Blast Furnace Stack*
}

\author{
By Koretaka Kodama, ${ }^{* *}$ Takehiro Horio, ${ }^{* *}$ and Noritoshi Inagaki ${ }^{* * *}$
}

\section{Synopsis}

The experimental stack furnace was specially designed with the purpose to reproduce the conditions in industrial blast furnaces. Here the reproduced conditions are counter-flow of gas against solids, temperature gradient within the furnace, and the content of carbon monoxide in reducing gas.

The measured degree of reduction was compared with the ratio of the indirect reduction in an operating blast furnace; the experimental degree of reduction of ores at the lower end of the reduction zone agreed well with the ratio of the indirect reduction in the blast furnace.

Having established that the experimental furnace fairly faithfully duplicated the conditions in the blast furnace, the effects of the following major factors on the reduction were studied;

i. Residence time of the burden in the reduction zone of the experimental stack furnace

ii. Flow-rate of reducing gas

iii. Reducibility of ores

iv. Ore/coke ratio in the charge

The effect of the pre-reduction of the some portion of the burden (sponge iron) on the reduction was also studied. The experimental results were successfully used to estimate coke rates for blast furnaces using sponge iron. The estimated coke rates were compared against the actual results from blast furnaces using sponge iron.

Finally, the reduction process in the experimental stack furnace was studied mathematically, calculations being based on a rate equation for the reduction of iron ores. The equation was solved numerically using an electronic computer. The mathematical results showed the same effects from the major factors as did the experimental.

\section{Introduction}

Iron-making has progressed rapidly, coupling lowered fuel consumption with raised productivity. The developments in blast furnace operations have included preliminary processing of burden (ore sizing, self-fluxing sintering, and pelletizing), preparation of blast (raised blast temperature, humidity control, fuelinjection, and oxygen enrichment), high top pressure operation, and so on.

To date the influences of these improvements on the performance of blast furnaces has been analyzed, for the most part, by experimental operation of industrial blast furnaces. However, the experimental operation with large blast furnaces is very much costly both in time and money.

The indirect reduction of iron ores in the blast furnace is one of the major factors that are related to furnace performance. Recently, the reduction of iron ores and the heat transfer in a counter-flow reaction have been studied by many investigators. ${ }^{1-5)}$ Further, numerous attempts have been made to establish mathematical models which give a quantitative ex- planation of the blast furnace process. ${ }^{6)-10}$ ) Their results seem to give a fairly clear picture of the actual blast furnace process. However, some additional data are needed to check these calculated results.

In the present study, experiments were performed with an experimental stack furnace under the condition of counter-flow of gas against solids, reproducing the reduction of iron ores in the blast furnace. Then, the reduction of iron ores in the experimental stack furnace was calculated with a mathematical model based on a rate equation of the reduction of iron ores. The effect of sponge iron on the reduction of iron ores was experimentally studied. The coke rate was estimated for the operation with sponge iron by calculation of the thermal and material balances.

\section{Reduction Test with an Experimental Stack Furnace}

\section{Outline}

The experiments were performed in such a way that indirect reduction within the blast furnaces was to be reproduced in the experimental stack furnace. Therefore, the essential conditions were that (1) the degree of reduction of ores at the lower end of the reduction zone in the experimental furnace should be equal to the ratio of the indirect reduction of ores in blast furnaces and that (2) the composition of the top-gas of the experimental furnace should be identical with that of the top-gas of blast furnaces.

Experimental conditions were as follows:

i. Counter-flow of gas and solid: ores and coke were charged onto the top of the experimental furnace while the reducing gas was introduced from the bottom.

ii. Temperature distribution: the temperature rose gradually in the higher part of the furnace, but the lower in the furnace, the gentler was the temperature increase. (See Fig. 1)

iii. Charging: coke and ores were charged separately, and ore/coke ratio was 2.5. The size of ores was $13 \mathrm{~mm} \pm 1 \mathrm{~mm}$ and the size range of coke was 10 to $20 \mathrm{~mm}$.

iv. Gas composition: the content of carbon monoxide in reducing gas was $41 \%$, approximately equal to the sum of the contents of the carbon monoxide and carbon dioxide in blast furnace top-gas.

v. Residence time of the charge: the charge

* Presented at the 66th ISIJ Meeting, October, 1963 in Nagoya, the 71st, April, 1966 in Tokyo, and the 72 nd, October, 1966 in Osaka. English version received December 28, 1966.

** Technical Research Institute, Yawata Iron \& Steel Co., Ltd., Kitakyushu.

*** Overseas Technical Co-operation Department, Yawata Iron \& Steel Co., Ltd., Marunouchi, Chiyoda-ku, Tokyo. 


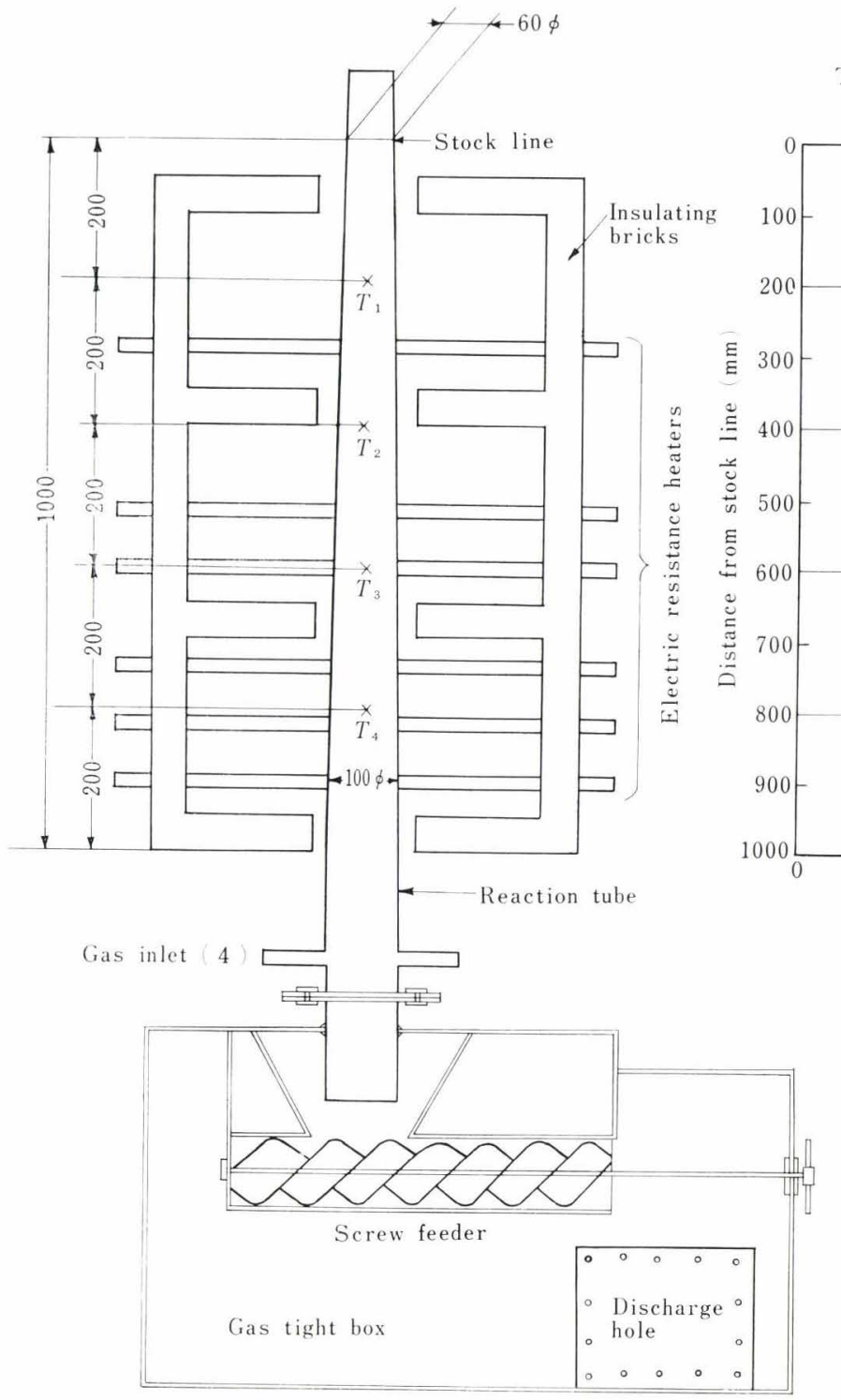

Temperature distribution in furnace

Fig. 1.

Experimental stack furnace (unit $\mathrm{mm}$ ) $T_{1}-T_{4}$ thermocouples

descended, within $200 \mathrm{~min}$, to the lower end of the reduction zone, which was $1 \mathrm{~m}$ below the top of the charge column.

vi. Flow-rate of reducing gas: the flow-rate of gas was kept at $0.024 \mathrm{Nm}^{3} / \mathrm{min}$ for the residence time of $200 \mathrm{~min}$. This flow-rate was so determined that a unit quantity of ore was reduced by the same quantity of gas in the experimental furnace as in the actual blast furnace.

\section{Apparatus and Method}

\section{Test Apparatus}

The test apparatus is shown in Photo. 1 and its cross-section is shown in Fig. 1. The vertical reaction tube was made of stainless steel and surrounded by insulating bricks. The tube was heated by electric resistance heaters on either side. The temperatures of the upper, middle, and lower part of the furnace were controlled separately to keep the temperature distribution approximately the same as in the blast furnace stack described in other reports. ${ }^{11)-15)}$ The temperature gradient was steep at the upper part and gentle at the lower part, as shown in Fig. 1.

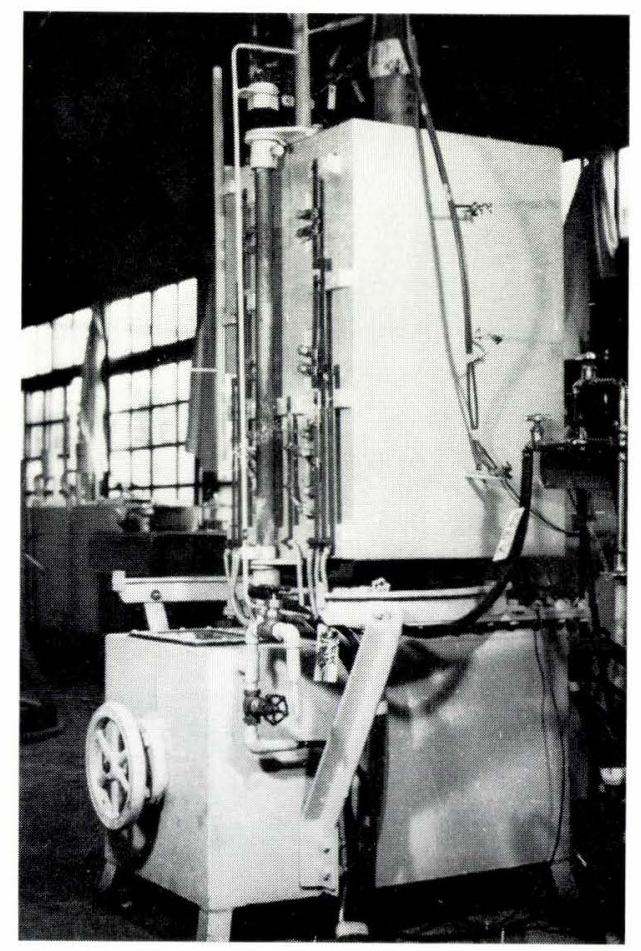

Photo. 1. Experimental stack furnace 
The lower end of the reaction tube was connected to a gas-tight box equipped with a screw feeder. The screw feeder, being periodically rotated, discharged coke and the partially reduced ores from the tube, ensuring the descent of the charge in the furnace. The particle size of ores of $13 \mathrm{~mm}$ was about the same as that of pellets.

The reaction tube was equipped with four gas-inlets. $\mathrm{CO}$ content of $41 \%$ in the reducing gas is about the same as the $\mathrm{CO}$ content of the gas which enters the indirect reduction zone in blast furnaces. The reducing gas was produced in a gas reformer in which a mixture of air and $\mathrm{CO}_{2}$ was converted into $\mathrm{CO}$ plus $\mathrm{N}_{2}$ by a charcoal layer at $1100^{\circ} \mathrm{C}$. The charcoal was preliminary dried and the moisture in the air was removed to decrease $\mathrm{H}_{2}$ in the reducing gas. $\mathrm{H}_{2}$ content of the gas was about $2 \%$, which is about the same as that of the top gas of blast furnaces. The reformed gas was, at first, lead to reservoirs. The gas from the reservoirs was purified of $\mathrm{CO}_{2}$ and $\mathrm{O}_{2}$ and dried, and then blown into the reaction tube. The gas was not pre-heated, and so the temperature of the burden near the gasinlets was lowered. Therefore, the reduction zone was supposed to extend only $1 \mathrm{~m}$ below the stock line (top of the charge column) and the volume of the reduction zone was calculated to be $5200 \mathrm{~cm}^{3}$.

\section{Experimental Procedure}

At the beginning of the experiment, the lower half of the reaction tube was filled with a mixture of coke and the prereduced ores obtained by the preceding similar experiments. The upper half was then filled with the alternate layers of ores and coke. The furnace was heated to obtain the predetermined distribution of temperature. Then the gas was supplied through the gas-inlets. When the top of the charge column was lowered to the predetermined level, an additional charge (380 g of ore and $152 \mathrm{~g}$ of coke, corresponding to an ore/coke ratio of 2.5 ) was added. During the experiment, the top-gas was analyzed continuously in order to check whether the reaction in the furnace had reached a stationary state or not. The stationary state was reached when the layer of charge on the top of the charge column at the start reached the bottom of the furnace.

Usually, the experiment was continued for another $60 \mathrm{~min}$, and then the gas in the various parts of the tube was taken for analysis. The reducing gas was stopped and nitrogen gas was flown, and heating was stopped. After the furnace was cooled to room temperature, the burden was taken out of the tube and analyzed chemically to calculate the degree of reduction.

Eq. (1) was used for this calculation,

$$
Y=\frac{(\mathrm{O})_{1}-(\mathrm{O})_{2}}{(\mathrm{O})_{1}} \times 100
$$

where, $\quad Y:$ degree of reduction (\%),

$(\mathrm{O})_{1}$ : initial content of removable oxygen (\%),

$(\mathrm{O})_{2}$ : content of removable oxygen, after reduction (\%).

Note: "removable oxygen" means oxygen combined with iron in ores.

\section{Effects of the Residence Time and the Flow-Rate of Re-} ducing Gas

The residence time of the charge and the flow-rate of the reducing gas influence the composition of the top-gas and the degree of reduction of ores at the lower end of the reduction zone. (Hereafter, this degree of reduction will be referred to as "final degree of reduction ".) The residence time and the flow-rate were, therefore, important factors in obtaining the same progress of reduction in the experimental stack furnace as in the blast furnace stack. Thus, the composition of the top-gas of the experimental furnace should be equal to that of blast furnace top-gas. At the same time, the final degree of reduction should be equal to the ratio of indirect reduction in blast furnaces.

Some experiments were carried out on Goa ore to study the effects of the residence time and the gas flowrate. Table 1 shows the chemical analysis of Goa ore and of other ores tested later. The results are shown in Figs. 2 and 3. It was found that the final degree of reduction increases with an increase in either residence time or flow-rate.

A statistical analysis of the operating data of the Tobata blast furnaces had shown that the ratio of the indirect reduction of Goa ore was about 75\% ${ }^{16}{ }^{16}$ Experimentally, when the residence time $\left(t_{r}\right)$ and the flow-rate $\left(v_{g}\right)$ were kept at $200 \mathrm{~min}$ and $0.024 \mathrm{Nm}^{3} / \mathrm{min}$,

Table 1. Chemical analysis of ores (\%)

\begin{tabular}{l|c|r|c}
\hline & $\mathrm{Fe}$ & $\mathrm{Fe}^{++}$ & $\begin{array}{c}\text { Removable } \\
\text { oxygen* }\end{array}$ \\
\hline Goa & 60.04 & - & 25.80 \\
Marcona & 63.35 & 2.44 & 27.30 \\
Adrianitas & 68.30 & 13.88 & 27.42 \\
Joyo & 48.30 & 16.10 & 18.45
\end{tabular}

* Oxygen combined with iron in ores.

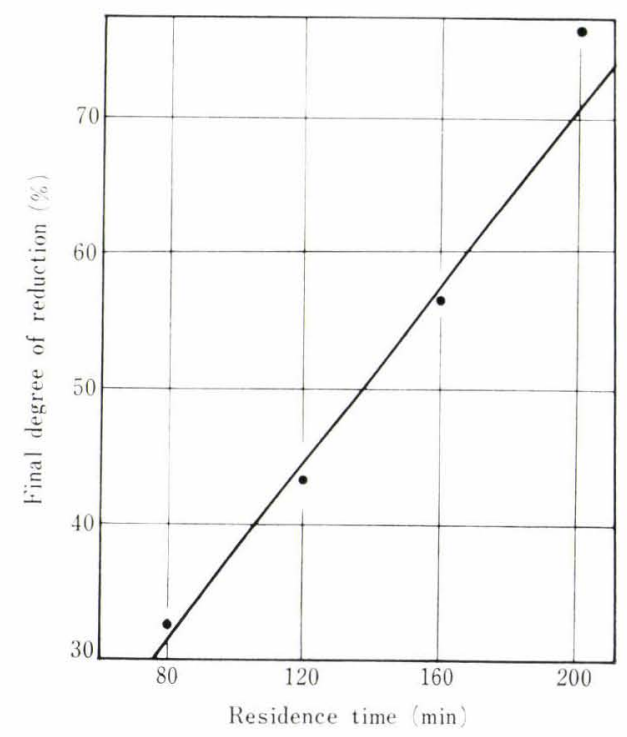

Fig. 2. Effect of residence time on the final degree of reduction of Goa ore Gas flow-rate : $0.024 \mathrm{Nm}^{3} / \mathrm{min}$ 


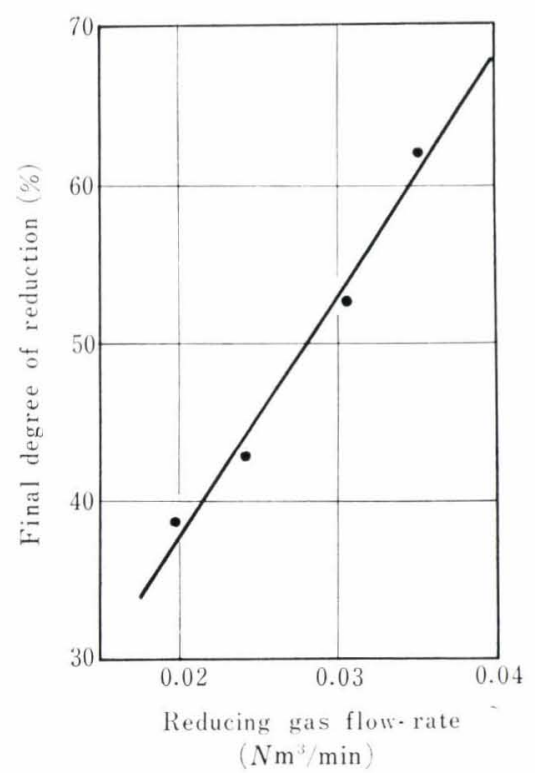

Fig. 3. Effect of reducing gas flow-rate on the final degree of reduction of Goa ore Residence time: $120 \mathrm{~min}$

respectively, the final degree of reduction of Goa ore was about the same as the above-mentioned ratio of indirect reduction. The chemical composition of the top-gas of the experimental stack furnace was also about the same as that of blast furnace top-gas.

Eq. (2) represents the amount of oxygen removed from ores in the experiment,

$$
\frac{16}{22.4}\left(\mathrm{CO}_{2}\right) v_{g}=(\mathrm{O}) \cdot W \cdot \frac{V_{i}}{t_{r}} \cdot \frac{Y_{e}}{100}
$$

where, $\left(\mathrm{CO}_{2}\right)$ : $\mathrm{CO}_{2}$ content of top-gas $(\%)$,

$v_{g}$ : flow-rate of reducing gas $\left(\mathrm{N} \mathrm{m}^{3} / \mathrm{min}\right)$,

(O) : content of removable oxygen in ore burden (\%),

$V_{i}$ : volume of the reduction zone, $5200 \times 10^{-6} \mathrm{~m}^{3}$,

$t_{r}$ : residence time of charge $(\mathrm{min})$,

$W$ : weight of ore burden in $1 \mathrm{~m}^{3}$ of charge $\left(\mathrm{kg} / \mathrm{m}^{3}\right)$,

$Y_{e}$ : final degree of reduction $(\%)$.

Eq. (2)' shows the amount of oxygen removed from ores by $\mathrm{CO}$ in the blast furnace stack,

$$
\frac{16}{22.4}\left(\mathrm{CO}_{2}\right)^{\prime} v_{g}^{\prime}=(\mathrm{O})^{\prime} \mathrm{O} / \mathrm{C} \frac{W_{c}}{1440} \cdot \frac{Y_{i r}}{100}
$$

where, $\quad W_{c}:$ amount of coke charged $(\mathrm{kg} / \mathrm{day})$,

$\mathrm{O} / \mathrm{C}$ : ore/coke ratio of charge,

$Y_{i r}$ : the ratio of indirect reduction of ores in the blast furnaces $(\%)$.

Both $\left(\mathrm{CO}_{2}\right)$ and $\left(\mathrm{CO}_{2}\right)^{\prime}$ do not include the amount of carbon dioxide due to the reaction of the carbon deposition $\left(2 \mathrm{CO} \rightarrow \mathrm{C}+\mathrm{CO}_{2}\right)$ and due to the decomposition of lime stones $\left(\mathrm{CaCO}_{3} \rightarrow \mathrm{CaO}+\mathrm{CO}_{2}\right)$. Provided that $(\mathrm{O}),\left(\mathrm{CO}_{2}\right)$, and $Y_{e}$ in the experiment are equal respectively to $(\mathrm{O})^{\prime},\left(\mathrm{CO}_{2}\right)^{\prime}$, and $Y_{\text {ir }}$ in blast furnaces, Eq. (3) is obtained from Eqs. (2) and (2)',

$$
t_{r} v_{g}=v_{g}^{\prime} V_{i} W \frac{1440}{W_{c} \mathrm{O} / \mathrm{C}}
$$

When practical data of the blast furnaces at Tobata are put into Eq. (3), the product $t_{r} v_{g}$ is in the range of about 4 to 5 .

The present experimental conditions of $t_{r}=200 \mathrm{~min}$, and $v_{g}=0.024 \mathrm{Nm}^{3} / \mathrm{min}$ correspond to a $t_{r} v_{g}$ of 4.8 . This value is within the range calculated by Eq. (3) for the blast furnace practice. Consequently, the ore was considered to be reduced in the experimental stack furnace by the same amount of gas as in the blast furnaces.

The above calculations and the experimental results proved that ores in the experimental stack furnace were reduced in the same way as in the blast furnaces. This fact will be further confirmed in the next paragraph, where the experimental results on various other ores are compared with the result of the statistical analysis of the blast furnace operation.

In Fig. 4 are shown two examples of the reduction progress of Goa ore in the experimental stack furnace.

\section{Effects of Reducibility of Ores}

Further, the experiments were performed on Marcona, Adrianitas, and Joyo ores under the conditions as shown in the table below:

The results are shown in Fig. 5.

\begin{tabular}{l|c|c}
\hline & (a) & (b) \\
\hline Residence time $(\mathrm{min})$ & 200 & 120 \\
Gas flow-rate $\left(\mathrm{Nm}^{3} / \mathrm{min}\right)$ & 0.024 & 0.035 \\
Ore/coke ratio & 2.5 & 2.5 \\
\hline
\end{tabular}

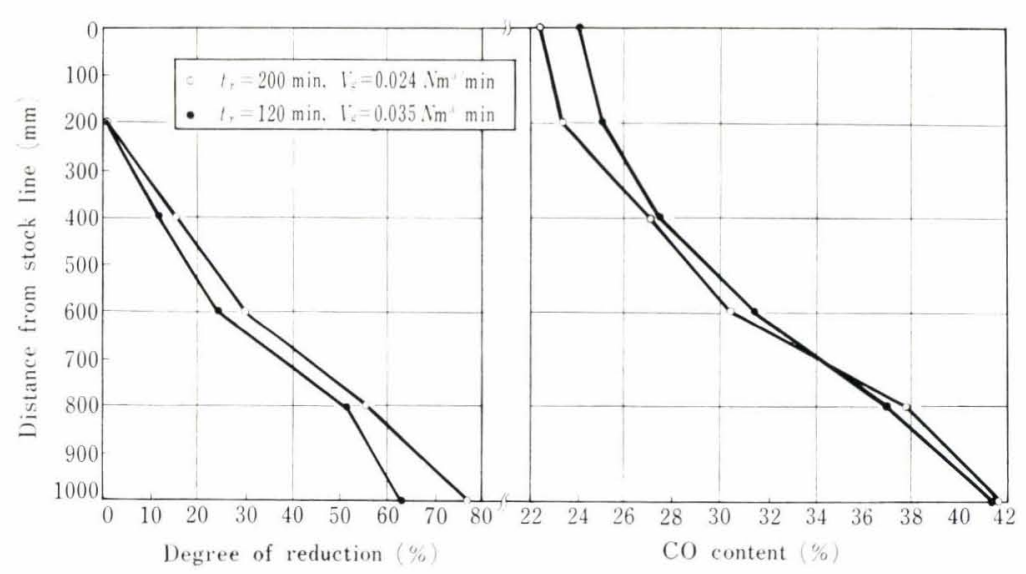

Fig. 4.

Reduction of Goa ore in the experimental stack furnace 

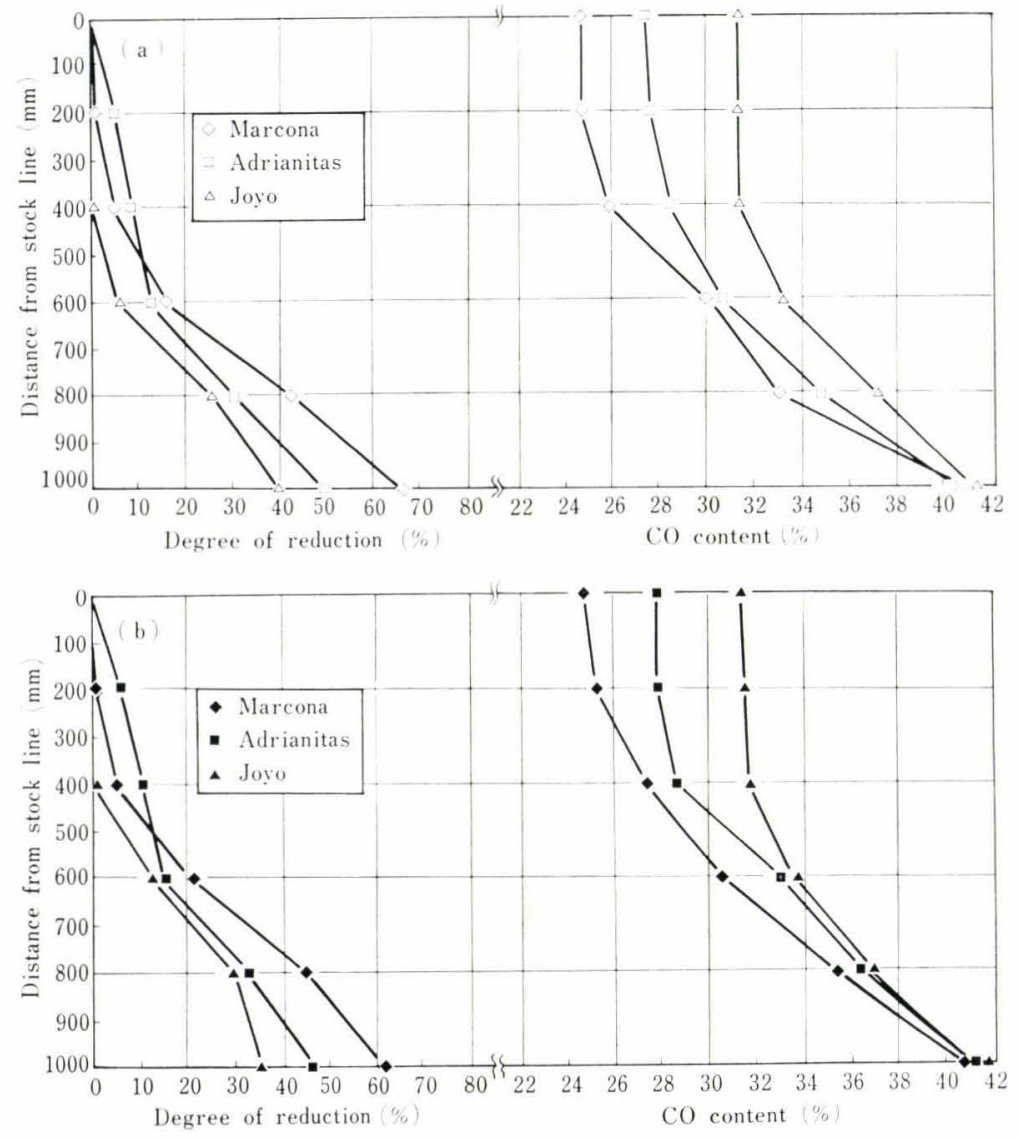

Fig. 5 .

Reduction of Marcona, Adrianitas, and Joyo ores (a) $t_{r}=200 \mathrm{~min}, V_{g}=0.024 \mathrm{Nm}^{3} / \mathrm{min}$

(b) $t_{r}=120 \mathrm{~min}, V_{g}=0.035 \mathrm{Nm}^{3} / \mathrm{min}$
In Fig. 6, the final degree of reduction is plotted against the reducibility measured by "Gakushin Method" (a method recommended by The Japan Society for the Promotion of Science).

Meanwhile, a relation between the reducibility of ores and the ratio of the indirect reduction in blast furnaces had been clarified with a statistical analysis of operating data ${ }^{16}$ of the blast furnaces at Tobata.

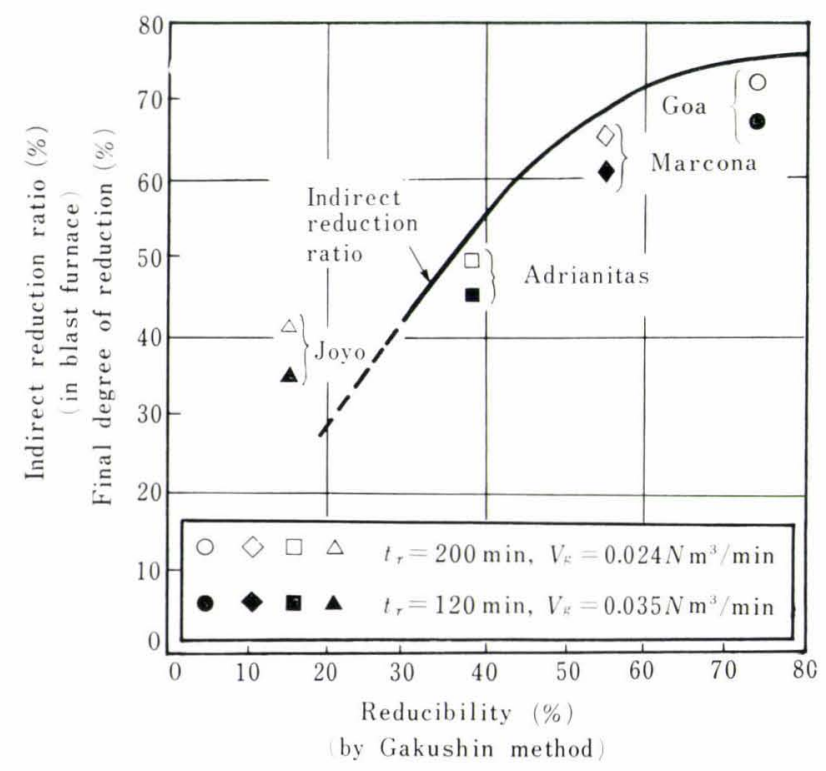

Fig. 6. Relation of the "reducibility to the final degree of reduction or the ratio of the indirect reduction
The relation thus obtained is also shown by a curve in Fig. 6.

Fig. 6 shows that the relation between the reducibility and the final degree of reduction in the experimental furnace is about the same as the relation between the reducibility and the ratio of the indirect reduction in the blast furnaces; the gradient is gentler at higher reducibilities. This fact can be explained by the unfavorably higher content of the carbon dioxide gas corresponding to higher final degree of reduction. The final degree of reduction of Joyo ore was not so low in spite of its low reducibility, because its low initial content of removable oxygen has the same effect as a low ore/coke ratio. The effect of ore/coke ratio on the reduction will be treated in the next paragraph. From these results, it was considered that the reduction of iron ores proceeds in the experimental stack furnace in the same way as in the blast furnace stack. So, the final degree of reduction was considered to correspond to the ratio of the indirect reduction in blast furnaces.

\section{Effect of Ore/Core Ratio}

In order to determine the effect of ore/coke ratio on the final degree of reduction, a series of experiments was performed on Goa, Marcona and Joyo ores. These experiments were carried out with ore/coke ratios of 1.5, 2.5, and 3.5. Fig. 7 shows the results that the ore/ coke ratio affects both the final degree of reduction and the composition of the top-gas. This fact can be explained as follows:

(1) An increase in ore/coke ratio results in an increase in the amount of ores in the furnace. It further 


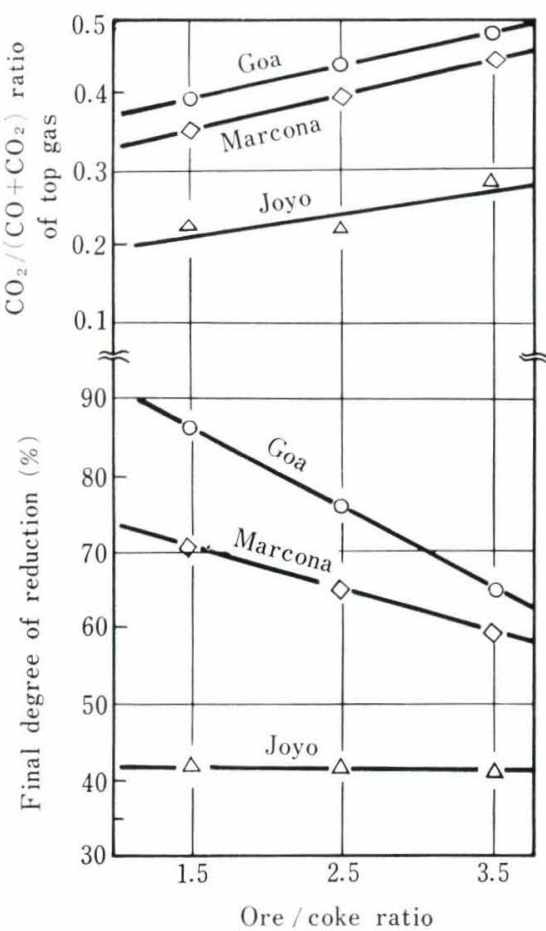

Fig. 7. Effect of ore/coke ratio on the final degree of reduction

(Experiments)

$$
t_{r}=200 \mathrm{~min}, V_{g}=0.024 \mathrm{Nm}^{3} / \mathrm{min}
$$

increases the amount of oxygen to be removed from ores in the furnace.

(2) If the final degree of reduction remains constant, $\mathrm{CO}_{2}$ content of the gas in the furnace increases corresponding to an increase in the amount of oxygen to be removed. This relation can be explained by Eq. (2).

(3) $\mathrm{CO}_{2}$ retards the reduction of ores.

Coke rate always changes in response to changes in the ore/coke ratio. So, any factor, which influences coke rate, also influences the reduction of iron ores. This fact should always be taken into consideration in the analysis of blast furnace performance.

\section{Conclusions of the Above Experiments}

(1) The final degree of reduction increases with an increase in the flow-rate of reducing gas.

(2) The final degree of reduction increases also with an increase in residence time of ores.

(3) The final degree of reduction decreases with an increase in ore/coke ratio of charge.

(4) The relation between the reducibility and the final degree of reduction can be represented by a parabolic curve; its gradient is gentle at higher reducibilities. The same relation has been observed between the reducibility and the ratio of the indirect reduction.

(5) The final degree of reduction is approximately the same as the ratio of the indirect reduction. The composition of the top-gas of the experimental stack furnace is also approximately the same as that of the blast furnace top-gas.
Consequently, the indirect reduction within the blast furnace is considered to be reproduced in the experimental stack furnace.

\section{Application in Estimating Coke Rate}

\section{Blast Furnace Operation with Sponge Iron}

In 1965, sponge iron was experimentally used at Higashida No. 6 blast furnace (hearth diameter $6.2 \mathrm{~m}$, inner volume $648 \mathrm{~m}^{3}$ ) in the Yawata works. ${ }^{17}$ ) The sponge iron was prepared by a rotary kiln from a mixture of blast furnace flue dust and oxygen converter sludge. The chemical analysis of the sponge iron is shown in Table 2. During the test period I, ores were partially replaced by the sponge iron and during the period II, sinter was partially replaced. The operating data of base and test periods are shown in Table 3. It is found that coke rate decreases considerably with the use of sponge iron.

Table 2. Chemical analysis of sponge iron and sinter (\%)

\begin{tabular}{l|r|r|r|r}
\hline & $\begin{array}{c}\text { Total } \\
\text { Fe }\end{array}$ & Met. Fe & $\mathrm{Fe}^{++}$ & $\begin{array}{c}\text { Removable } \\
\text { oxygen }\end{array}$ \\
\cline { 5 - 6 } $\begin{array}{l}\text { Sponge iron } \\
\text { Period I }\end{array}$ & 68.88 & 41.07 & 26.77 & 8.14 \\
Period II & 67.14 & 38.58 & 25.23 & 7.08 \\
Laboratory* & 68.14 & 39.58 & 27.08 & 8.39 \\
Sinter (Tobata) & 57.41 & & 9.92 & 23.28
\end{tabular}

* Samples used for stack furnace experiments.

\section{Effect of Sponge Iron on the Reduction of Ores}

The result of the stack furnace experiments was used to estimate the influence of sponge iron on coke rate. The result of the calculation was compared with the data of actual blast furnace operation.

The experiments were performed on burden consisting of sponge iron and sinter. The purpose of these experiments was to clarify the effect of admixed sponge iron on the reduction of iron ore (in this case, sinter). Sinter produced at Tobata sintering plant was used in the experiments. Its chemical analysis is shown in Table 2. The experimental conditions were as follows; residence time, $86 \mathrm{~min}$, gas flow-rate, 0.028 $\mathcal{N} \mathrm{m}^{3} / \mathrm{min}$, burden/coke ratio, 2.5 , sponge iron ratios, $0 \%, 20 \%$, and $50 \%$. The results (see Fig. 8 ) shows that addition of sponge iron increases the final degree of reduction of sinter. This can be explained as follows:

(1) The amount of oxygen combined with iron in the burden is decreased by the addition of the less oxidized sponge iron.

(2) So, $\mathrm{CO}_{2}$ content of the gas in the furnace decreases and $\mathrm{CO}$ content increases, affecting the rate of ore reduction.

The addition of sponge iron thus has the same effect on iron ore reduction as a decrease in ore/coke ratio. (See $I I-5$ )

\section{Calculation of the Effect of Sponge Iron on Coke Rate}

According to the authors' experience, coke rate depends on the amount of solution loss carbon. This 
Table 3. Results of experimental operation with sponge iron

\begin{tabular}{|c|c|c|c|c|c|c|}
\hline & \multicolumn{3}{|c|}{ Period I } & \multicolumn{3}{|c|}{ Period II } \\
\hline & Base & $10 \%$ & $20 \%$ & Base & $30 \%$ & $40 \%$ \\
\hline Sinter ratio $(\%)$ & 50.6 & 36.6 & 30.9 & 50.5 & 50.3 & 50.3 \\
\hline Sponge iron ratio $(\%)$ & - & 11.3 & 20.2 & - & 29.9 & 39.8 \\
\hline Hot metal output (t/day) & 856 & 833 & 918 & 958 & 1046 & 1048 \\
\hline Coke rate $(\mathrm{kg} / \mathrm{t}$-hot metal) & 516 & 509 & 474 & 490 & 428 & 400 \\
\hline Fuel rate $(\mathrm{kg} / \mathrm{t}$-hot metal $)($ coke + injected fuel $)$ & 516 & 509 & 474 & 528 & 463 & 436 \\
\hline Ore/coke & 2.96 & 3.01 & 3.14 & 3.16 & 3.56 & 3.74 \\
\hline Blast volume $\left(\mathrm{Nm}^{3} / \mathrm{min}\right)$ & 750 & 736 & 750 & 906 & 902 & 908 \\
\hline Blast temperature $\left({ }^{\circ} \mathrm{C}\right)$ & 956 & 929 & 1002 & 966 & 987 & 981 \\
\hline Basicity of slag & 1.22 & 1.21 & 1.27 & 1.25 & 1.28 & 1.31 \\
\hline $\mathrm{CO}_{2}(\%)$ & 16.8 & 16.4 & 16.1 & 14.0 & 13.4 & 13.0 \\
\hline Top gas $\{\mathrm{CO}(\%)$ & 24.6 & 24.8 & 25.5 & 24.6 & 25.3 & 25.9 \\
\hline $\mathrm{H}_{2}(\%)$ & 2.6 & 2.9 & 2.5 & 3.9 & 4.1 & 4.2 \\
\hline Hot metal $\{\mathrm{Si}(\%)$ & 0.58 & 0.62 & 0.53 & 0.64 & 0.63 & 0.67 \\
\hline analysis I S (\%) & 0.030 & 0.031 & 0.033 & 0.028 & 0.033 & 0.024 \\
\hline
\end{tabular}

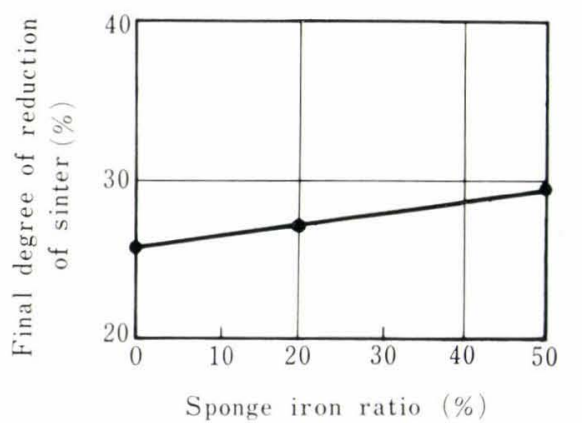

Fig. 8. Effect of sponge iron on the final degree of reduction of sinter

amount can be calculated as a function of the ratio of the indirect reduction. In the case of a blast furnace running with a burden containing sponge iron, the coke rate can be calculated by subtracting, from the base coke rate, the change due to the added sponge iron. The procedure of the calculation may be outlined as follows:

(1) Calculation of the amount of solution loss carbon when sponge iron is not used.

Note: "Solution loss carbon " means the carbon gasified by the carbon solution reaction $\left(\mathrm{CO}_{2}+\mathrm{C} \rightarrow 2 \mathrm{CO}\right)$ or by the direct reduction of iron oxides (e.g. $\mathrm{FeO}+\mathrm{C} \rightarrow \mathrm{Fe}+\mathrm{CO}$ ).

(2) Calculation of the indirect reduction ratio when sponge iron is used. This calculation is based on the experimental results described in $\boldsymbol{I I I}-2$.

(3) Calculation of the amount of solution loss carbon when sponge iron is used.

(4) Calculation of the effect of sponge iron on coke rate. This calculation is based on thermal and material balances. The details of these calculations are as follows.

\section{Calculation of the Amount of Solution Loss Carbon}

The amount of carbon gasified by carbon solution reaction (or direct reduction) is calculated by follow- ing equation:

$$
C S_{1}=\frac{12}{16} K_{1} \sum \frac{p_{i}}{100} \cdot \frac{(\mathrm{O})_{i}}{100} \cdot\left(1-\frac{Y_{i}}{100}\right)
$$

where, $\quad C S_{1}$ : amount of solution loss carbon $(\mathrm{kg} / \mathrm{t}$-hot metal),

$K_{1}$ : burden ratio $(\mathrm{kg} / \mathrm{t}$-hot metal),

$p_{i}$ : proportion of ore " $i$ " in burdens (\%),

$(\mathrm{O})_{i}$ : content of removable oxygen of ore " $i$ " $(\%)$,

$Y_{i}:$ indirect reduction ratio of ore " $i$ " $(\%)$.

The indirect reduction ratio of each ore, $Y_{i}$, can be estimated from its reducibility measured in accordance with the Gakushin method. The relation between the indirect reduction ratio and the reducibility is shown in Fig. 6.

\section{Calculation of the Ratio of the Indirect Reduction When Sponge Iron is Used}

From the experimental results in $\mathbf{I I I}$-2, it was assumed that the indirect reduction ratio, $Y_{i}$, is increased by admixed sponge iron. The change, $\Delta Y_{i}$, was calculated by an equation based on the following assumptions :

(1) The change, $\Delta Y_{i}$, is proportional to the ratio of the indirect reduction of each ore, $Y_{i}$.

(2) The change, $\Delta Y_{i}$, increases linearly with a decrease in the ratio of ore (not including sponge iron) to coke, $B_{2}$ in Eq. (6).

The experimental results showed that the final degree of reduction of sinter increased by $0.144 \%$ with a decrease of $1 \%$ in the above defined ore/coke ratio.

A topochemical process was defined as follows; ${ }^{21)}$ "Reduction occurs at a distinct interface between the outer layer (metal) and the inner core (oxide) and the interface remains parallel to the outer surface of the ore as it moves inward ". If the topochemical process is assumed in the reduction of ores, the rate of reduction, $d Y / d t$, can be expressed as follows:

$$
\frac{d Y}{d t}=-\frac{3 r^{2}}{r_{o}^{3}} \cdot \frac{d r}{d t}
$$


where, $\quad r$ radius of unreduced core $(\mathrm{mm})$,

$r_{o}$ : radius of ore lump $(\mathrm{mm})$,

$d r / d t$ : velocity of inward movement of reaction interface $(\mathrm{mm} / \mathrm{min})$.

When sponge iron was used, $\mathrm{CO}$ content of gas changed in the experimental stack furnace. Now, the content of $\mathrm{CO}$ influences the rate of reduction. Accordingly, $d r / d t$ increased in the experimental furnace when sponge iron was added. Also, when sponge iron is actually used in a blast furnace, $d r / d t$ usually increases in the same way as it did in the experimental furnace.

But the change in $d Y / d t$ in blast furnaces is not same as the change in $d Y / d t$ in the experimental furnace, because the radii of ore lumps and the unreduced cores in blast furnaces are different from those in the experimental furnace. At the stack furnace experiments described in $\boldsymbol{I I I}-2$, the radius of sinter lump was $6.5 \mathrm{~mm}$ and the radius of unreduced core at the lower end of the reduction zone was calculated to be $5.8 \mathrm{~mm}$, corresponding to the final degree of reduction of $28 \%$. In this case, Eq. (5) takes the following forms:

$$
\left(\frac{d Y}{d t}\right)_{s}=-0.37\left(\frac{d r}{d t}\right)_{s}
$$

In the blast furnace, the average radius of sinter is $10 \mathrm{~mm}$ and the radius of unreduced core of the partially reduced sinter is calculated to be $6.0 \mathrm{~mm}$, corresponding to its indirect reduction ratio of $78 \%$. In this case, Eq. (5) takes the following form:

$$
\left(\frac{d Y}{d t}\right)_{b}=-0.11\left(\frac{d r}{d t}\right)_{b}
$$

Provided $(d r / d t)_{s}$ be equal to $(d r / d t)_{b}$, the ratio, $(d Y / d t)_{b} /$ $(d Y / d t)_{s}$, is about 0.3. On the assumption that the ratio of $(d Y / d t)_{b}$ to $(d Y / d t)_{s}$ is a constant at any corresponding levels of blast furnaces and the experimental furnace, the effect of the addition of sponge iron on the indirect reduction ratio is calculated to be about three tenths of its effect on the final degree of reduction, which is obtained in the experiments.

Thus, the change in the ratio of the indirect reduction in the blast furnace stack, $\Delta Y_{i}$, can be represented as follows :

$$
\lrcorner Y_{i}=0.3\left(\frac{B_{1}-B_{2}}{B_{1}}\right) \frac{Y_{i}}{Y_{s}}\right\lrcorner Y_{s}
$$

where, $B_{1}$ : ore/coke ratio (when sponge iron is not used),

$B_{2}$ : ratio of ore (not including sponge iron) to coke (when sponge iron is used),

$\Delta Y_{s s}:$ increase in the final degree of reduction of sinter due to $1 \%$ decrease in ore/coke ratio $\left(B_{2}\right)$, i.e. $0.144 \%$,

$Y_{s}:$ indirect reduction ratio of sinter $(\%)$,

$Y_{i}$ : indirect reduction ratio of burden " $i$ " $(\%)$.

The reducibility of sponge iron was $38.8 \%$.

$B_{2}$ is to be calculated as a quotient; i.e. (ore consumption, $\mathrm{kg} / \mathrm{t}$-hot metal)/(coke rate, $\mathrm{kg} / \mathrm{t}$-hot metal). When sponge iron is used, the burden ratio can be calculated by Eq. (7),

$$
K_{1} \sum p_{i}(\mathrm{Fe})_{i}=K_{2} \sum p_{i}(\mathrm{Fe})_{i}
$$

where, $K_{1}$ : burden ratio (when sponge iron is not used) (kg/t-hot metal),

$K_{2}$ : burden ratio (when sponge iron is used) $(\mathrm{kg} / \mathrm{t}$-hot metal),

$(\mathrm{Fe})_{i}: \quad$ Fe content of burden " $i$ " $(\%)$.

The ratio of ore (not including sponge iron) to coke, $B_{2}$, is equal to $K_{2}\left(1-p_{s} / 100\right) /\left(\right.$ coke rate), where $p_{s}$ is the sponge iron ratio in burden $(\%)$. However, because coke rate is not yet obtained when sponge iron is used, so $B_{2}$ cannot be calculated in this stage.

\section{Calculation of the Change in the Amount of Carbon of Solution Loss}

When sponge iron is used, the amount of carbon of solution loss is calculated by Eq. (4)',

$$
C S_{2}=\frac{12}{16} K_{2} \Sigma \frac{p_{i}}{100} \cdot \frac{(\mathrm{O})_{i}}{100}\left(1-\frac{Y_{i}}{100}-\frac{\Delta Y_{i}}{100}\right)
$$

The change in the amount of carbon of solution loss due to the added sponge iron can be obtained by subtracting $C S_{2}$ from $C S_{1}$, as follows :

$$
\lrcorner C S=C S_{1}-C S_{2}
$$

\section{Calculation of the Coke Rate}

Eq. (9) has been obtained from a statistical analysis of practical data of Tobata blast furnaces, ${ }^{18)}$

$$
k_{1} c_{p} \mathcal{T}_{b}+q_{1} C^{\prime}+q_{2} M=k_{2}
$$

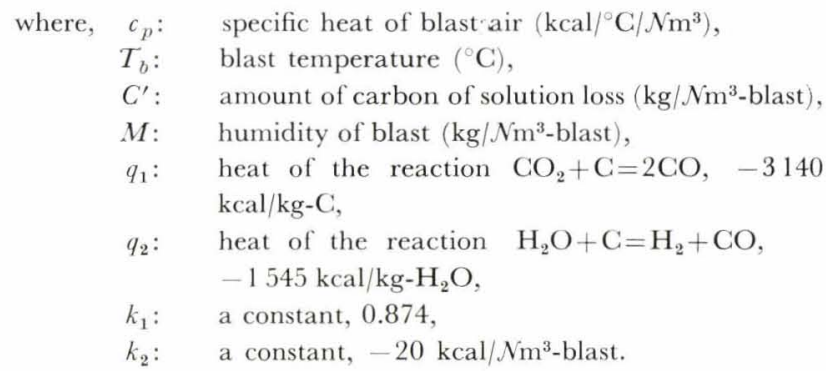

$k_{1}$ and $k_{2}$ were determined by the statistical analysis.

This equation refers to the thermal balance of a blast furnace. In the blast furnace operation, the thermal condition is often disturbed by the fluctuation in the amount of carbon lost by the reaction of carbon solution, an endothermic reaction. The reaction of carbon solution is caused by the residual oxygen in iron oxides coming into the high temperature zone. The amount of carbon of solution loss is influenced by many factors such as ore/coke ratio, moisture in coke and ores, iron content of burden materials, amount of oxygen to be removed from burden materials, carbon content of coke, amount of fuel injected and so on. If the thermal condition changes as a result of some uncontrollable change in the above factors, the blast furnace operator will control the ore/coke ratio of charge in order to keep the amount of solution loss carbon (and therefore the thermal condition) at certain levels. As coke rate is a function of ore/coke ratio, the amount of solution loss carbon is, theoretically, closely related to coke rate. 
The coke rate is the total of several coke consumptions, as shown in Eq. (10),

$$
C R=100 \frac{C_{t}+C_{s}+C_{m}+C_{h}}{C_{f}}
$$

where, CR: coke rate $(\mathrm{kg} / \mathrm{t}$-hot metal),

$C_{t}$ : amount of carbon gasified by blast air $(\mathrm{kg} / \mathrm{t}-\mathrm{hot}$ metal),

$C_{s}$ : amount of solution loss carbon $(\mathrm{kg} / \mathrm{t}$-hot metal),

$C_{m}$ : amount of carbon going into hot metal $(\mathrm{kg} / \mathrm{t}-\mathrm{hot}$ metal),

$C_{h}$ : amount of carbon gasified by $\mathrm{H}_{2} \mathrm{O}$ in blast $(\mathrm{kg} / \mathrm{t}-$ hot metal),

$C_{f}:$ carbon content of coke $(\%)$.

On the basis of Eqs. (9) and (10), Eq. (11) is obtained for the calculation of the change in coke rate, ${ }^{16)}$

$$
\Delta C R=100\left(1-\frac{0.225 q_{1}}{k_{1} c_{p} T_{b}+q_{2} M-k_{2}}\right) \frac{\Delta C_{s}}{C_{f}}
$$

This equation is considered to be applicable to practical operation of blast furnaces within a certain range.

Finally, the change in coke rate can be calculated by Eqs. (4), (4)', (6), and (11).

\section{Results}

Fig. 9 shows the changes in coke rate calculated for the experimental operation of Higashida No. 6 blast furnace with sponge iron. Also Fig. 9 shows the results of the actual operations. As can be seen in this figure, the lines representing the results of calculations lie very close to the points representing the results of operations.

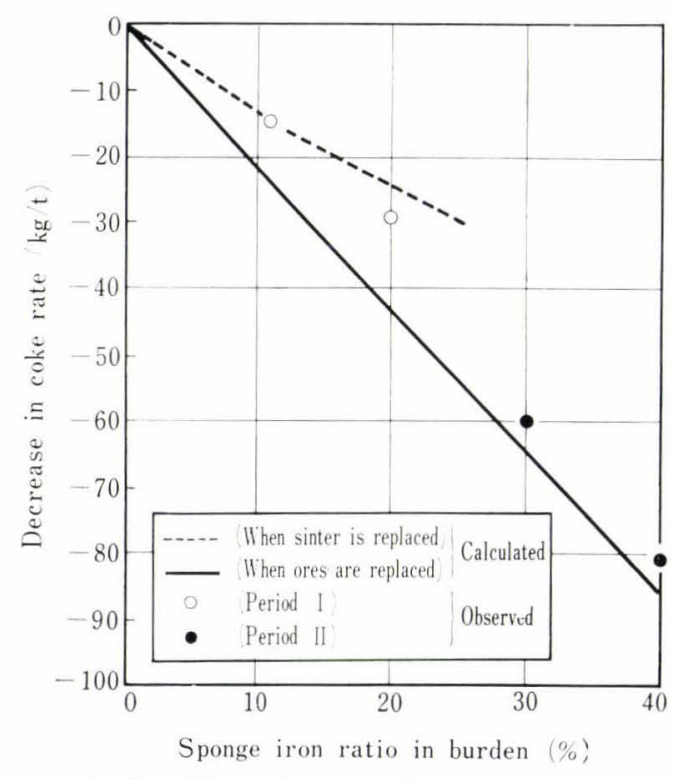

Fig. 9. Effect of sponge iron on coke rate

\section{Calculation of the Rate of Reduction in the Experimental Stack Furnace}

As concluded in Section $\boldsymbol{I I}$, the indirect reduction within the blast furnace can be reproduced in an ex- perimental stack furnace. The burden charged into blast furnaces generally consists of a mixture of ores. However, the experiment had to be carried out mostly on one kind of ore at a time, because identification between ores was very difficult when reduced: the stack furnace experiment on mixed-ore burden was practically impossible. Therefore, a method of calculations has to be developed for the estimation of the degree of reduction.

The calculation of the degree of reduction in the experimental stack furnace was studied on the basis of the rate equation of iron ore reduction.

\section{Rate Equations of Iron Ore Reduction}

The reduction of iron ores and its rate equation have been studied by many investigators and many rate equations were proposed. ${ }^{19)-27)}$ Although it is difficult to explain all phenomena of the reduction of the iron ores with a single formula, it seems possible to apply, with a sufficient accuracy, some of the proposed equations to the calculation of the reduction progress in the blast furnace stack. K. Kodama, A. Shigemi, and $\mathrm{T}$. Higashi ${ }^{28)}$ worked out the following rate equation for the reduction of iron ores, assuming the topochemical reaction and using the theory of absolute reaction rates $;^{29)}$

$$
\begin{aligned}
r_{o}\left(1-\sqrt[3]{1-\frac{Y}{100}}\right)= & k P\left\{\frac{(\mathrm{CO})}{100}-\frac{\left(\mathrm{CO}_{2}\right)}{100} C_{e}\right\} \mathcal{T} . \\
& \exp \left(-\frac{\Delta H}{R T}\right) \cdot t \ldots \ldots \ldots . . .
\end{aligned}
$$

where, $\quad Y:$ degree of reduction $(\%)$,

$r_{o}:$ radius of ore lump $(\mathrm{mm})$,

$k:$ rate constant $(\mathrm{mm} / \mathrm{atm} / \mathrm{deg} / \mathrm{min})$,

$P$ : pressure of gas (atm),

(CO): CO content of gas ( $\%)$,

$\left(\mathrm{CO}_{2}\right): \quad \mathrm{CO}_{2}$ content of gas $(\%)$,

$C_{e}$ : equilibrium $\mathrm{CO} / \mathrm{CO}_{2}$ ratio for the reduction of iron oxide to metal,

T: temperature $\left({ }^{\circ} \mathrm{K}\right)$,

$\Delta H:$ activation energy (cal/mole),

$R$ : gas constant, $1.986 \mathrm{cal} / \mathrm{mole} / \mathrm{deg}$,

$t$ : time $(\min )$.

The diffusion of the reactant and productant gases either through the gas film around the outer surface of ores or through the pores in ores was also studied. ${ }^{24), 25), 27)}$ But its effect was not reflected in Eq. (12). This is because (1) the flow velocity of reducing gas in the experimental furnace was as high as in the blast furnace, and the gas film was considered to be so thin that its effect could be reasonably neglected, and (2) the diffusion of gas through pores did not influence the reduction rate much until the degree of reduction exceeded a certain level (about 80\%). ${ }^{25)}$

Prior to the present study, experiments on the reduction of iron ores with mixtures of $\mathrm{CO}$ and $\mathrm{CO}_{2}$ at $700^{\circ}, 800^{\circ}$, and $900^{\circ} \mathrm{C}$ were performed in the authors' laboratory. ${ }^{30 \text { ) }}$ The result of these experiments showed that the reducing reaction with $\mathrm{CO}$ occurs at the $\mathrm{FeO} /$ Fe interface. Therefore, the $\mathrm{CO} / \mathrm{CO}_{2}$ ratio in equilibrium with $\mathrm{FeO}$ and $\mathrm{Fe}$ was used for the calculation 
in accordance with Eq. (12).

The reduction of $\mathrm{Fe}_{3} \mathrm{O}_{4}$ to $\mathrm{FeO}$ at high temperatures is generally explained by the diffusion of $\mathrm{Fe}$ in the solid phases. ${ }^{19), 20), 23), 26)}$ At temperatures below $570^{\circ} \mathrm{C}$, the $\mathrm{FeO}$ phase is unstable and $\mathrm{Fe}_{3} \mathrm{O}_{4}$ is reduced directly to metal. In the upper part of the experimental furnace, $\mathrm{CO} / \mathrm{CO}_{2}$ ratio of gas is about the same as that in equilibrium with both $\mathrm{Fe}_{3} \mathrm{O}_{4}$ and metal. Therefore, the rate of the reaction is supposed to be very low in the upper part of the furnace. However, as shown in Fig. 4, hematitic ores (Goa and Marcona) were actually reduced more than 10\% before reaching the level where the temperature was $700^{\circ} \mathrm{C}$.

In another reduction experiment, in which ores were reduced at $500^{\circ} \mathrm{C}$ by the gas with $\mathrm{CO} / \mathrm{CO}_{2}$ ratios less than 1, the hematitic ore (Goa) was found to be reduced by $10 \%$ within several minutes. Reduction of $\mathrm{Fe}_{2} \mathrm{O}_{3}$ to $\mathrm{Fe}_{3} \mathrm{O}_{4}$ corresponds to a degree of reduction of $11.11 \%$. Therefore, it was concluded that the reduction of $\mathrm{Fe}_{2} \mathrm{O}_{3}$ to $\mathrm{Fe}_{3} \mathrm{O}_{4}$ proceeds rapidly, and that this reaction prevails in the upper part of the furnace. But there was not sufficient data to formulate the rate of the reduction of $\mathrm{Fe}_{2} \mathrm{O}_{3}$ to $\mathrm{Fe}_{3} \mathrm{O}_{4}$. Accordingly, in the present calculation, it was assumed that the reduction of $\mathrm{Fe}_{2} \mathrm{O}_{3}$ to $\mathrm{Fe}_{3} \mathrm{O}_{4}$ is finished by the time it reaches the $400 \mathrm{~mm}$ (below the stock line) level.

The rate constant, $k$, and the activation energy, $\Delta H$, were determined by another series of reducibility tests. The test conditions were as follows:

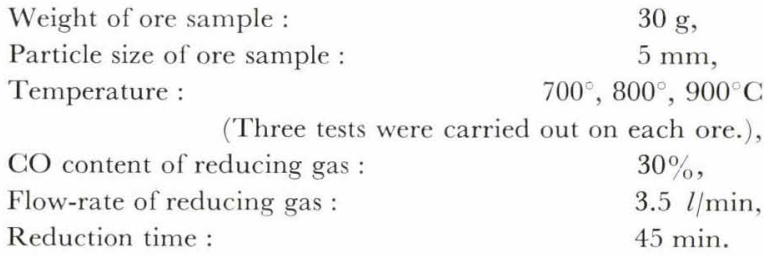

The test results are shown in Table 4. Also shown in the same table are the rate constant and the activation energy of ores currently used in Japan.

\section{Calculation Method}

The degree of reduction can be calculated as a function of $r$ (the radius of unreduced core) and $r_{o}$ (the radius of ore lump) by following Eq. (13):

$$
Y=\left(1-\frac{r^{3}}{r_{o}^{3}}\right) \times 100
$$

When Eq. (13) is put into Eq. (12), the latter is transformed into the following form :

$$
r=r_{o}-k\left\{\frac{(\mathrm{CO})}{100}-\frac{\left(\mathrm{CO}_{2}\right)}{100} C_{e}\right\} \cdot T \cdot \exp \left(-\frac{\Delta H}{R T}\right) \cdot t
$$

The velocity of the inward movement of the reaction interface is represented by the differential equation,

$$
\frac{d r}{d t}=-k\left\{\frac{(\mathrm{CO})}{100}-\frac{\left(\mathrm{CO}_{2}\right)}{100} C_{e}\right\} \cdot T \cdot \exp \left(-\frac{\Delta H}{R T}\right)
$$

The descending velocity of the burden in the furnace is expressed as follows:

$$
\frac{d x}{d t}=V_{i} /\left(\pi a^{2} t_{r}\right)
$$

where, $x$ : the distance from the stock line $(\mathrm{mm})$, $a$ : the radius of the furnace at the level $x(\mathrm{~mm})$.

From Eqs. (15) and (16), Eq. (17) is obtained,

$$
\frac{d r}{d x}=-k\left\{\frac{(\mathrm{CO})}{100}-\frac{\left(\mathrm{CO}_{2}\right)}{100} C_{e}\right\} \cdot T \cdot \exp \cdot\left(-\frac{\Delta H}{R T}\right) \cdot \frac{\pi a^{2} t_{r}}{V_{i}}
$$

The differential of Eq. (13) with respect to $x$ is as follows :

$$
\frac{d Y}{d x}=-\frac{3 r^{2}}{r_{o}^{3}} \cdot \frac{d r}{d x}
$$

and Eq. (19) shows the differential equation of the amount of oxygen removed by CO,

$$
\frac{16}{22.4} v_{g} \frac{d(\mathrm{CO})}{d x}=\frac{(\mathrm{O}) W V_{i}}{t_{r}} \cdot \frac{d Y}{d x}
$$

These differential equations are difficult to solve. The degree of reduction of ores in the furnace does not always change continuously; for example, the degree of reduction of smaller ore lumps remains constant after having reached $100 \%$. Consequently, only numerical solutions were obtained in this study.

The calculation was carried out as follows:

(1) The charge column in the furnace was divided

\begin{tabular}{|c|c|c|c|c|c|}
\hline & \multicolumn{3}{|c|}{ Degree of reduction (\%) } & \multirow{2}{*}{ Rate constant } & \multirow{2}{*}{$\begin{array}{c}\text { Activation } \\
\text { energy } \\
\text { (cal/mole) }\end{array}$} \\
\hline & $700^{\circ} \mathrm{C}$ & $800^{\circ} \mathrm{C}$ & $900^{\circ} \mathrm{C}$ & & \\
\hline Goa & 41.5 & 66.2 & 79.6 & $2.47 \times 10^{-2}$ & 12580 \\
\hline Ipoh & 38.3 & 47.2 & 73.6 & $2.92 \times 10^{-3}$ & 7750 \\
\hline Marcona & 14.5 & 33.5 & 58.6 & $7.24 \times 10^{-2}$ & 15800 \\
\hline Adrianitas & 2.1 & 17.0 & 38.4 & $3.07 \times 10$ & 30800 \\
\hline Chile & 11.7 & 28.7 & 59.0 & $2.40 \times 10^{-1}$ & 18650 \\
\hline Kedah & 53.8 & 66.1 & 82.5 & $1.35 \times 10^{-3}$ & 5350 \\
\hline Joyo & 5.2 & 10.5 & 15.4 & $1.25 \times 10^{-3}$ & 10000 \\
\hline
\end{tabular}
into many successive layers and the reduction rate and the material balance were calculated for each thin layers from the top of the reduction zone to the bottom.

(2) A series of calculations were performed for the top-gas composition initially supposed.

Table 4. Rate constant and activation energy for reduction of ores 
(3) The calculated gas composition at the lower end of the reduction zone was compared with that of the actual experiment $(\mathrm{CO}=41 \%)$.

(4) If the calculated gas composition was different from that of the experiment, the calculation was repeated after changing the initial condition, the top-gas composition.

(5) These calculations were stopped when the calculated gas composition finally came into the range of $41 \% \pm 0.3$.

This trial and error method required a great deal of calculating, so an electronic computer was used.

\section{Calculation Results}

\section{Reduction Progress}

The reduction of Goa, Marcona, Adrianitas and Joyo ores in the experimental furnace were studied: degree of reduction and gas composition in the furnace were calculated in accordance with the method outlined in $\boldsymbol{I V}-2$. The results are shown in Fig. 10. In the same figure are also shown the experimental results, which were already plotted in Figs. 4 and 5.

\section{Effect of Ore/Coke Ratio}

On the assumption of the separate charge of coke and ores, $W$ (weight of burden in $1 \mathrm{~m}^{3}$ of charge, $\mathrm{kg} / \mathrm{m}^{3}$ ) is a function of ore/coke ratio in following equation :

$$
W=\frac{\mathrm{O} / \mathrm{C}}{\mathrm{O} / \mathrm{G} / \rho_{o}+1 / \rho_{\mathrm{c}}}
$$

where, $\rho_{o}$ : bulk density of ores $\left(\mathrm{kg} / \mathrm{m}^{3}\right)$,

$\rho_{c}$ : bulk density of coke $\left(\mathrm{kg} / \mathrm{m}^{3}\right)$
Table 5 shows the bulk density and calculated $W$ of the charge which consists of coke and ores. Fig. 11 shows the calculated final degree of reduction and the top-gas composition. In Fig. 11, CO content of gas in the furnace and, accordingly, the final degree of reduction is decreasing with increasing ore/coke ratio of the charge. The same tendency was already observed in the experimental results shown in Fig. 7.

Table 5. Bulk density and calculated value of $W$

\begin{tabular}{l|c|c|c|c|} 
& $\begin{array}{c}\text { Bulk } \\
\text { density } \\
\left(10^{3} \mathrm{~kg} / \mathrm{m}^{3}\right)\end{array}$ & \multicolumn{3}{|c}{$W\left(\mathrm{~kg} / \mathrm{m}^{3}\right)$} \\
\cline { 3 - 5 } & 1.52 & 438 & 611 & 737 \\
\hline Goa & 1.85 & 463 & 661 & 811 \\
Marcona & 1.5 & $\mathrm{O} / \mathrm{C}=2.5$ & $\mathrm{O} / \mathrm{C}=3.5$ \\
Adrianitas & 2.50 & 493 & 725 & 909 \\
Joyo & 2.00 & 470 & 678 & 835 \\
Coke & 0.41 & - & - & - \\
\hline
\end{tabular}

\section{Effect of Gas Flow-Rate and the Residence Time}

In the practical operation of blast furnaces, an increase in blast volume is always accompanied by an increase in gas flow-rate and a decrease in the residence time of ores. Accordingly, the product of gas flowrate and the residence time remains nearly constant. The preceding experiments showed that the final degree of reduction increases with an increase either in the gas flow-rate or in the residence time. Thus, the question arises as to which of the two-the residence time or the gas flow-rate- has the greater effect on the reduction of iron ores in blast furnace; the question
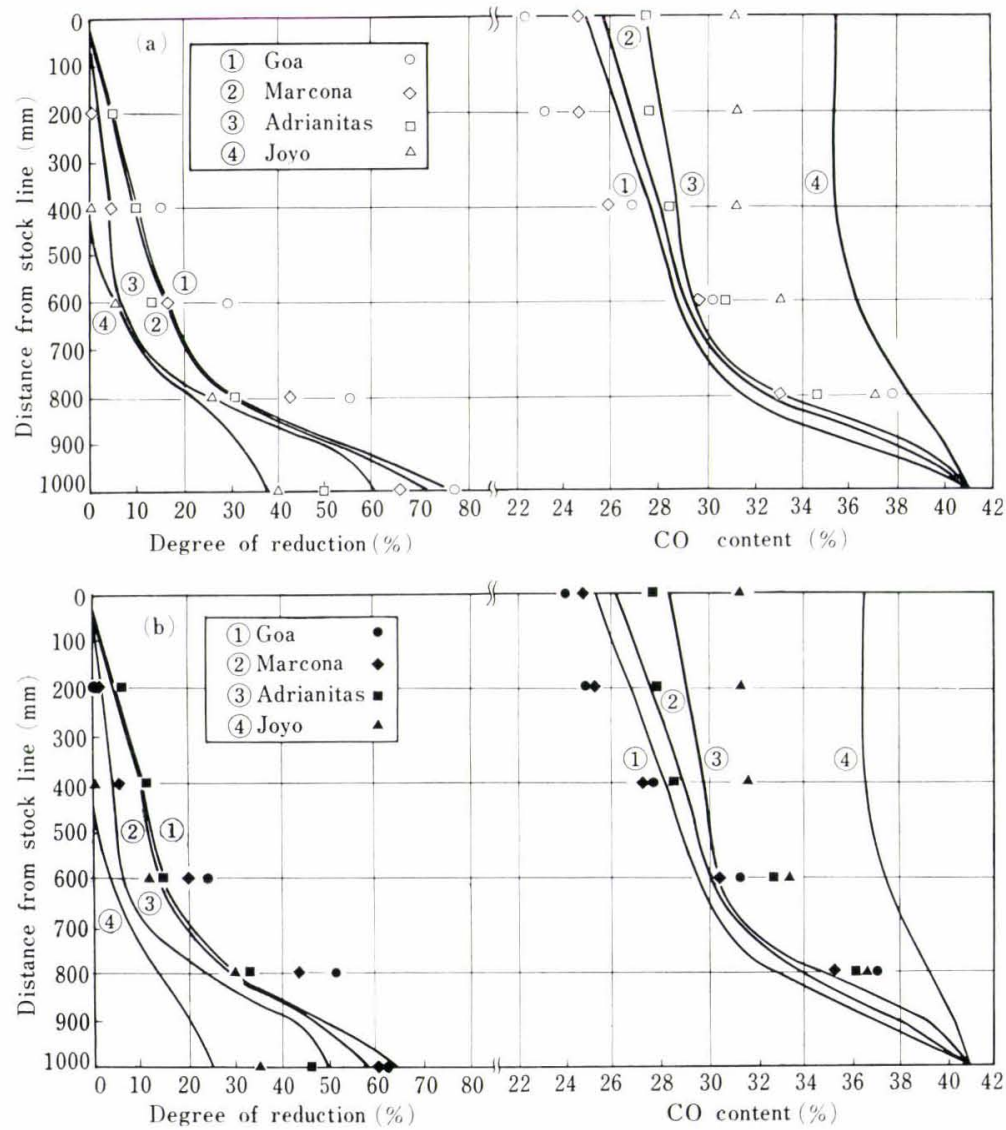

Fig. 10

Calculation results of reduction process in the experimental stack furnace

(a) $t_{r}=200 \mathrm{~min}, V_{g}=0.024 \mathrm{Nm}^{3} / \mathrm{min}$, $W=600 \mathrm{~kg} / \mathrm{m}^{3}$

(b) $t_{r}=120 \mathrm{~min}, V_{g}=0.035 \mathrm{Nm}^{3} / \mathrm{min}$, $W=600 \mathrm{~kg} / \mathrm{m}^{3}$ 


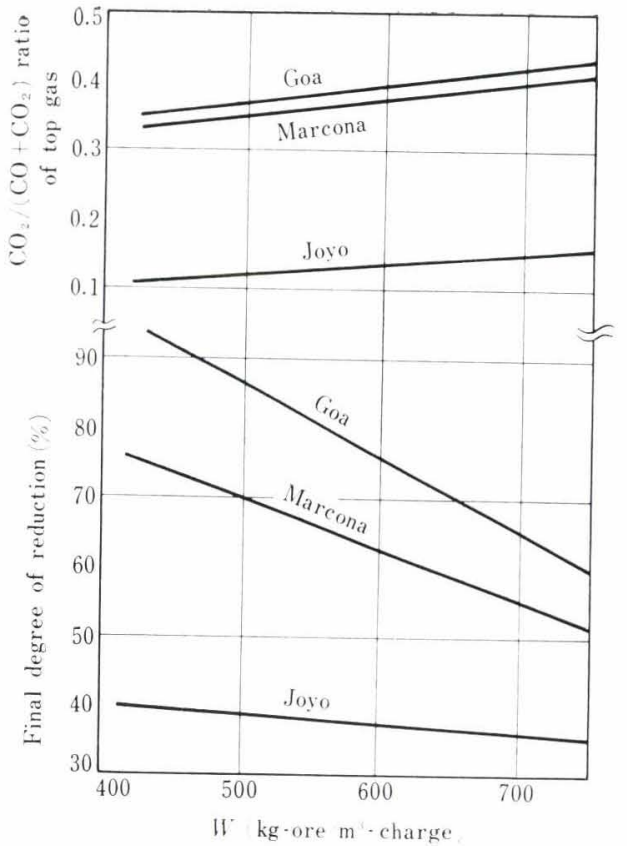

Fig. 11. Effect of ore/coke ratio on the final degree of reduction

(Calculation)

is how the indirect reduction ratio of iron ores is influenced by the change in the blast volume.

A series of experiments were performed, in which the residence time and the gas flow-rate were changed in such a way that the product, $t_{r} v_{g}$, remained constant. The calculations were also carried out for such cases. Fig. 12 shows that both of the two final degrees of reduction (observed and calculated) were lowered by a decrease in the residence time in spite of an increase in flow-rate. Therefore, the effect of the residence time on the iron ores was found to be greater than that of the flow-rate. Accordingly, in the practical operation of a blast furnace, the ratio of the indirect reduction of ores is supposed to decrease with an increase in blast volume.

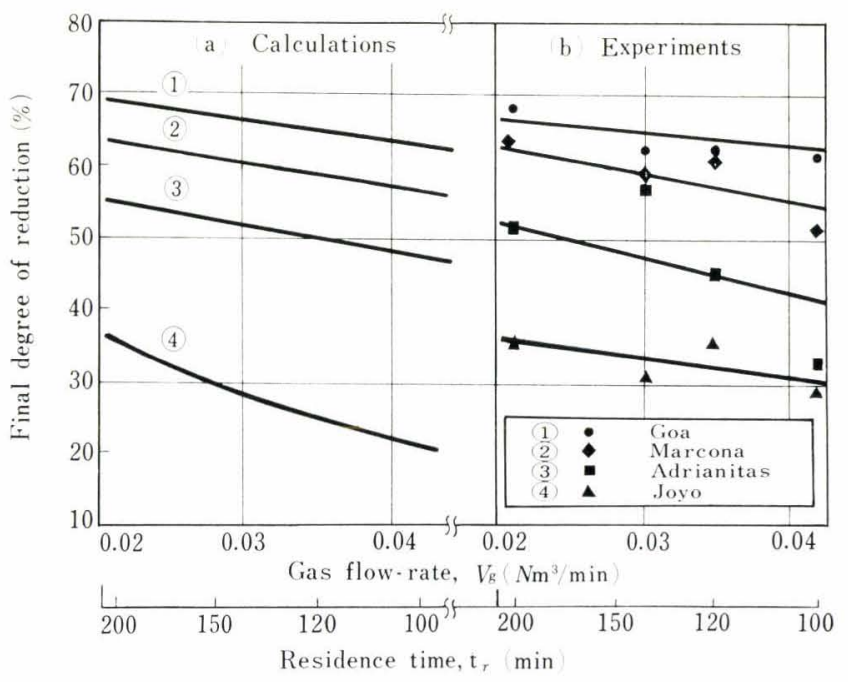

Fig. 12. Effect of gas flow-rate and residence time on the final degree of reduction

$t_{r} \times V_{g}=4.2$ constant

\section{Comparison with the Experimental Results}

The final degree of reduction calculated was plotted against the observed values in the experiments on various ores in Fig. 13. The figure shows that the calculated results agree satisfactorily with the experimental results. As previously mentioned, the experimental results of the degree of reduction are about the same as the ratio of the indirect reduction of ores in blast furnaces. Accordingly, if chemical analysis, rate constant, activation energy and bulk density of raw materials are obtained by laboratory tests, it should be possible to estimate the ratio of the indirect reduction from calculation of the final degree of reduction. Furthermore, it seems feasible that the similar method could be applied to the calculation of reduction progress of ores in the actual blast furnace. The heat transfer between solids and gases will be included in future calculations.

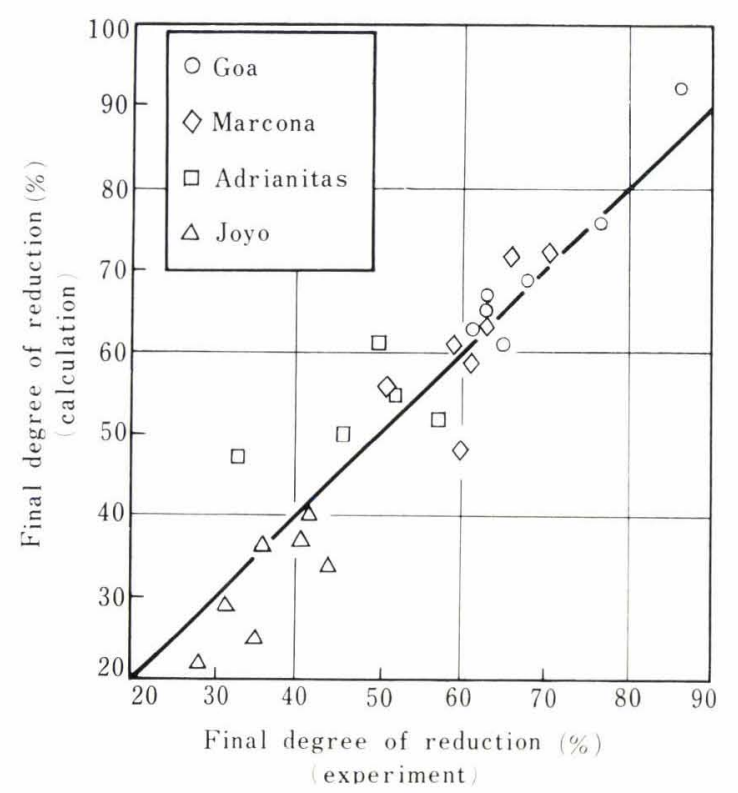

Fig. 13. Calculation results and experimental results of the final degree of reduction

\section{Conclusions}

(1) The present experiments by the stack furnace reproduced approximately the same progress of reduction of iron ores as in the blast furnace stack. The experimental results showed that the final degree of reduction (the degree of reduction of ores at the lower end of the reduction zone):

(i) Increased with an increase in the residence time (length of time the charge is in the furnace).

(ii) Increased with an increase in the flow-rate of reducing gas.

(iii) Decreased with an increase in the ore/coke ratio.

(iv) Increased with increased reducibility of the ore. This phenomenon can be represented graphically as a parabolic curve. Its gradient increase is gentle at the higher reducibilities.

(v) Closely approximated the ratio of the indirect 
reduction as attained in actual blast furnace operation. (Also top-gas in the experimental furnace closely approximated blast furnace top-gas.)

(2) The experiments on the burden containing sponge iron showed that an addition of sponge iron, like a decrease in ore/coke ratio, increases the reducing power of gas in the furnace. This experimental result was used to estimate coke rate for the experimental operation with sponge iron at Higashida No. 6 blast furnace. The coke rate was calculated on the basis of the thermal and material balances. The calculated coke rate agreed well with the actual results.

(3) The progress of reduction of ores in the experimental stack furnace was determined also by the calculation. This calculation is based upon the rate equation of iron ore reduction, which was studied in the authors' laboratory. The calculated effects of the flow-rate of reducing gas, of the residence time, of ore/coke ratio and of the reducibility of ores upon the degree of reduction were about the same as those observed in the actual experiments.

Both experiments and calculations showed that residence time has greater effect than has gas flow-rate on reduction, i.e. the ratio of the indirect reduction of ores in blast furnaces decreases with an increase in blast volume.

(4) In the present study, the rate of the reduction of iron ores in the experimental stack furnace, as a small model of the blast furnace stack, was studied in a mathematical way.

Calculation of the rate of reduction of iron ores in the blast furnace stack will be investigated, next.

Indirect reduction in the upper part of a blast furnace is only one of many reactions in a blast furnace. However, in order to clarify the relation between indirect reduction and blast furnace performance, it is necessary to study the reactions at the high temperature zone. The following should be taken into consideration:

i. Mechanism of reduction of silica by carbon, (reduction of silica by carbon in molten iron, effect of $\mathrm{FeO}$ in slag on the reduction of silica, reaction between coke and slag),

ii. The rate of reduction of $\mathrm{FeO}$ in slag,

iii. Heat transfer among gas, coke, and molten metal at the melting zone, etc.

The overall mathematical model, in which abovementioned reactions and heat transfer are taken into account, will explain the blast furnace process satisfactorily. The model will also clarify the effects of various factors on blast furnace performance.

\section{REFERENCES}

1) S. I. Privalov, V. N. Timofeev, and B. A. Bokovikov: STAL in English, (1960), 4.

2) K. Hedden and G. Sommer: Arch. Eisenhüttenw., 35 (1964), 9.

3) M. S. Kurchatov: STAL in English, (1964), 177.

4) L. von Bogdandy and R. Wartmann: Arch. Eisenhüttenw., 36 (1965), 221.

5) T. Soma: Tetsu-to-Hagané, 52 (1966), 1372.

6) A. L. Hodge: J. Iron Steel Inst. (U.K.), 199 (1961), 6.

7) J. M. Ridgion: J. Iron Steel Inst. (U.K.), 200 (1962), 389.

8) G. A. Flierman and J. M. Van Langen: Report of Amsterdam Session, International Conference on Iron and Steelmaking, March 1965.

9) H. Beer, L. Diefenbach, and K. Hedden: Report of Amsterdam Session, International Conference on Iron and Steelmaking, March 1965.

10) I. Muchi: Tetsu-to-Hagané, 52 (1966), 1079.

11) G. Heynert and J. Willems: Stahl u. Eisen, 79 (1959), 1545.

12) E. Schürmann, W. Zischkale, and D. Ischebec: Stahl $u$. Eisen, 80 (1960), 854.

13) J. Michard, P. Dancoisne, and G. Chanty: Blast Furnace, Coke Oven, and Raw Materials Conference, 20 (1961), 329.

14) B. L. Lazarev, B. I. Kitaev, and Yu. G. Yaroshenko: STAL in English, (1961), 162.

15) B. L. Lazarev, B. A. Bokovikov, N. M. Babushkin, V. N. Timofeev, V. V. Chervotkin, and S. I. Privalov: STAL in English, (1965), 429.

16) K. Kodama, K. Ono, T. Horio, and H. Kanoshima: Tetsuto-Hagané, 51 (1965), 1763.

17) Y. Shiraishi, K. Ono, A. Takeuchi, N. Hiramoto, Y. Mizuno, K. Yamaguchi, and H. Kanoshima: Tetsu-to-Hagané, 52 (1966), 313.

18) Y. Fukagawa, T. Yamamoto, Y. Abe, and N. Inagaki: Tetsu-to-Hagané, 50 (1964), 1607.

19) J. O. Edström: J. Iron Steel Inst. (U.K.), 175 (1953), 289.

20) J. O. Edström and G. Bitsianes: Trans. Met. Soc., AIME, 203 (1955), 760.

21) G. Bitsianes and T. L. Joseph: Trans. Met. Soc., AIME, 203 (1955), 639.

22) W. M. McKewan: Trans. Met. Soc., AIME, 224 (1962), 2.

23) V.J. Moran and A. E. Jenkins: J. Iron Steel Inst., (U.K.), 199 (1961), 26.

24) W. K. Lu: Trans. Met. Soc., AIME, 227 (1963), 203.

25) K. Mori: Tetsu-to-Hagané, 50 (1964), 2259.

26) K. H. Urlich and K. Bohnenkamp: Arch. Eisenhüttenw., 36 (1965), 611.

27) A. Moriyama, J. Yagi, and I. Muchi: J. Japan Inst. Metals, 29 (1965), 528.

28) K. Kodama, A. Shigemi, and T. Higashi: Tetsu-to-Hagané, 47 (1961), 271.

29) S. Glasstone, K. H. Laidler, and H. Eyring: The Theory of Rate Processes, McGraw-Hill Book Co., New York, (1941).

30) Unpublished. 